\title{
O PRINCÍPIO DA PROIBIÇÃO DO RETROCESSO SOCIAL E SUA IMPORTÂNCIA NA CONTEMPORANEIDADE
}

\section{The principle of the prohibition of social decline and its importance for actual days}

\author{
Marina de Oliveira de Vasconcellos ${ }^{1}$ \\ Fernando Vieira Luiz²
}

Resumo: O presente artigo objetiva discutir o princípio da proibição do retrocesso social e sua importância e aplicação na jurisprudência pátria, sobretudo no Supremo Tribunal Federal (STF). Para tanto, conceituar-se-á o princípio estudado, objetivando o rigor acadêmico necessário. Após, verificar-se-á a necessidade de assegurar os direitos fundamentais e manter uma ordem constitucional íntegra, com a explicação da segurança jurídica. Por fim, verificar-se-á a aplicação do princípio da proibição do retrocesso social na jurisprudência brasileira, principalmente na Corte Constitucional.

\begin{abstract}
This article aims to discuss the principle of the prohibition of social regression and its importance and application in the courts, especially at the Supreme Court (STF). First, this specific principle is conceptualized, aiming the necessary academic rigor. After that, I analyze the fundamental rights and the security to maintain our constitutional order. Finally, I explore how courts, mainly the STF, apply the principle of prohibition of social regression in Brazil.
\end{abstract}

1 Graduada em Direito (Unisul); Advogada; Juíza Leiga em Florianópolis. E-mail: marinavcellos@gmail.com.

2 Juiz de Direito; Juiz Substituto TRE-SC; Doutorando em Direito (UFSC); LL.M. (University of Connecticut School of Law); Mestre em Direito Público (Unesa).

E-mail: fernandovieiraluiz@gmail.com 
Palavras-chave: Princípio do retrocesso social. Segurança Jurídica. Direitos Sociais.
Keywords: Principle of social regression. Legal security. Social Rights.

\section{INTRODUÇÃO}

A realização deste estudo deve-se à relevância do assunto e à tomada de consciência da importância dos direitos sociais como normas assecuratórias da dignidade da pessoa humana e do pleno desenvolvimento social.

Nossa Carta Magna de 1988 trouxe o Estado Social Democrático de Direito, reconhecendo os direitos sociais como direitos fundamentais e, portanto, base do nosso ordenamento jurídico, não apenas representando uma meta a ser cumprida ou um programa a ser seguido, mas sim, traduzindo-se como a maior finalidade do Estado, pois uma vez consagrados, estaremos diante de uma sociedade plena. Nesse contexto, cabe dizer que os direitos sociais passaram a ser reconhecidos em decorrência de grandes lutas e conflitos, que, infelizmente, são restringidos e flexibilizados ao invés de assegurados e consagrados.

Ao longo da história, o Estado funciona como um caleidoscópio, apresentando-se com diferentes roupagens. Nesse sentido, tem-se que as crises enfrentadas pelo liberalismo trouxeram mudanças significativas de cunho social, passando o Estado a tentar alcançar o bem-estar de todos, prestando serviços públicos que asseguram benefícios como: previdência social, saneamento, saúde, moradia, educação etc. Assim, o Estado altera o modelo constitucional para Estado do Bem-Estar Social. Esta intervenção efetiva no setor social propiciou a incorporação de direitos à sociedade contemporânea.

Infelizmente, o modelo do Estado do Bem-Estar Social encontrou dificuldades na sua efetivação, com a falta de recursos materiais para que o Estado cumpra seu papel. Com o 
enfraquecimento desse modelo, problema que se agravou pelo neoliberalismo, observa-se a diminuição do cumprimento dos direitos sociais.

O neoliberalismo, que prega principalmente a abstenção do Estado no âmbito econômico, tem causado nefastos efeitos na seara dos Direitos Sociais, com a flexibilização de direitos e a precarização das prestações sociais. Face ao exposto, visualiza-se a necessidade de políticas compensatórias e, mais do que isso, a manutenção dos direitos já adquiridos.

Nessa senda, conceituar-se-á o princípio da proibição do retrocesso social no Brasil, mostrando sua importância para a preservação dos direitos sociais já conquistados. Assim, de igual importância, abordar-se-á os princípios fundamentais e o da segurança jurídica, bem como, a aplicação deste princípio na Jurisprudência.

\section{CONCEITO}

Nascimento $^{3}$, ao falar sobre o princípio da proibição do retrocesso social, leciona que ele está estritamente ligado à segurança jurídica, inquestionável na nossa Constituição. Frente a isso, não poderá o Estado extirpar direitos fundamentais já conquistados, ou seja, objetiva proibir a diminuição de proteção aos bens jurídicos fundamentais já alcançados e implementados em determinada sociedade. Nessa senda, quando o Estado tende a diminuir ou restringir direitos fundamentais, atenta ao princípio da proibição do retrocesso.

Tremel ${ }^{4}$ leciona que a evolução dos ordenamentos jurídicos em geral e, principalmente em relação ao brasileiro, dada

3 NASCIMENTO, Rafael. O princípio da proporcionalidade como via de aferição do retrocesso social. Revista Petardo, Anuário PET. Santa Catarina: Fundação Boiteux. 2006. p. 322.

4 TREMEL, Rosangela. Princípio da Proibição do Retrocesso: Sua Importância e Necessidade de Ampliação do Entrenchment para Proteção dos Hipossuficientes. Disponível em: < http://www.advocaciapasold.com.br/artigos/arquivos/artigo_principio_do_nao_retrocesso_profa_rosangela_tremel.pdf> Acesso em: 10 out 2012. p. 1. 
à ordem constitucional vigente, torna-se evidente a aplicação de princípios que maximizam os direitos fundamentais. Por isso, o princípio da proibição do retrocesso é de observância cogente, impondo-se ao Poder Público o dever de implementar políticas públicas e manter as existentes, garantido o acesso aos cidadãos a direitos básicos. $\mathrm{O}$ autor, sobre a realidade dos nossos direitos fundamentais e a necessidade do princípio, discorre5:

A Constituição brasileira de 1988, na esteira das cartas modernas, atribuiu à segurança jurídica a importância que há muito era merecida. Basta olhar para a fundamentalização do direito adquirido, do ato jurídico perfeito e da coisa julgada (art. 5, XXXVI, da CF/88). Tal reconhecimento deve-se acima de tudo, à insustentabilidade de um Estado Democrático de Direito sem a estabilidade e a previsibilidade das relações jurídicas.

A segurança jurídica tem, portanto, valor inquestionável na defesa da sociedade frente aos atos de despotismo do poder público. Desse modo, após consolidada e delineada uma garantia fundamental, não pode, o Estado quebrar a relação de confiança construída com os administrados e extirpar dos seus patrimônios jurídicos os direitos fundamentais que os protegem das brutalidades do cotidiano.

Sabe-se, contudo, que somente a mudança permanece, haja vista as relações sociais serem frequentemente revistas pelas novas concepções culturais. $\mathrm{O}$ direito, de tal forma, nada mais é senão fruto de uma realidade societária. Assim sendo, não há que se idealizar um ordenamento que vigore perpetuamente, pois o direito tem de perseguir os anseios da sociedade e estar sempre à disposição dos sujeitos, sob pena de tornar-se ineficaz e cair no esquecimento.

Ocorre, entretanto, que algumas modificações no ordenamento jurídico se dão de maneira tão

5 NASCIMENTO, 2006, p. 336. 
abrupta e sem nenhuma causa justificante, que a materialidade do princípio da segurança jurídica é posta ao chão, restando somente a formalidade.

Segundo Sarlet ${ }^{6}$, no Brasil sua sede material está na Constituição brasileira de 1988, decorrendo dos princípios do Estado social e democrático de direito, da dignidade da pessoa humana, da máxima eficácia e efetividade das normas definidoras de direitos fundamentais, da segurança jurídica e da proteção da confiança, do valor social do trabalho e da valorização do trabalho humano. Sobre a fundamentação deste princípio, Sarlet ${ }^{7}$ leciona que:

Desde logo - e sem que se pretenda aprofundar todos os aspectos da questão - percebe-se que o tema ora versado desnuda também a genética e umbilical vinculação entre o direito à segurança social (aqui considerado como abarcando um conjunto de direitos sociais [simultaneamente positivos e negativos] garantidores de uma vida com dignidade) e do direito à segurança jurídica. Que a análise da problemática relativa à proibição de retrocesso no âmbito dos direitos sociais não dispensa uma prévia compreensão das diversas facetas da própria proibição de retrocesso no direito constitucional brasileiro, especialmente no tocante à sua fundamentação e seu significado, para que se possa, na seqüência, abordar alguns aspectos ligados ao alcance possível da proteção outorgada aos direitos sociais pela proibição de retrocesso, vai aqui assumido como corolário lógico-sistemático da limitação temática ora proposta.

Para Sarlet ${ }^{8}$, é enraizada a ideia de que um Estado de Direito está ligado a um Estado de segurança jurídica, sendo

6 SARLET, Ingo Wolfgang. Proibição de Retrocesso, Dignidade da Pessoa Humana e Direitos Sociais: manifestação de um constitucionalismo dirigente possível. Revista do Instituto de Hermenêutica Jurídica, Porto Alegre, n. 2, 2004. p. 2.

7 SARLET, 2004, p. 2 e 3.

8 SARLET, 2004, p. 4. 
então um princípio fundamental. $\mathrm{O}$ direito à segurança jurídica tem o sentido de um direito à proteção (por meio de prestações normativas e materiais) contra atos - do poder público e de outros particulares - violadores dos diversos direitos pessoais, garantindo a estabilidade da ordem jurídica. Sarlet ${ }^{9}$ discorre sobre o tema em questão:

Assim, parece certo que não se poderá, contudo, identificar pura e simplesmente o problema da concretização legislativa dos direitos fundamentais sociais - em que pesem suas inequívocas similitudes e seus aspectos comuns - com o da manutenção dos níveis gerais de proteção social alcançados no âmbito do Estado Social a partir do conjunto dos princípios que o densificam, já que esta problemática abrange toda e qualquer forma de redução das conquistas sociais, mesmo quando realizadas única e exclusivamente no plano da legislação infraconstitucional que diretamente concretiza os princípios da Justiça e do Estado Social que, paralelamente com o princípio do Estado de Direito e com o princípio democrático, encontraram ampla e expressa guarida na nossa Constituição. Aqui, em caráter ilustrativo, bastaria já apontar para os fundamentos e objetivos da nossa República, tal como enunciados nos já referidos artigos $1^{\circ}$ a $3^{\circ}$ da nossa Lei Fundamental, bem como os princípios basilares da ordem econômica, enunciados no artigo 170 . Neste contexto, poder-se-ia indagar, por exemplo, a respeito da possibilidade de desmontar-se, parcial ou totalmente (e mesmo com efeitos prospectivos), o sistema de seguridade social (incluindo os parcos benefícios no âmbito da assistência social e os serviços e prestações assegurados no âmbito do nosso precário Sistema Único de Saúde), o acesso ao ensino público e gratuito, a flexibilização dos direitos e garantias dos trabalhadores, entre tantas outras hipóteses que aqui poderiam ser referidas e que bem revelam como tal

9 SARLET, 2004, p. 10. 
problemática nos é próxima e está constantemente na ordem do dia (SARLET, 2004, p. 4).

Como os direitos sociais estão diretamente ligados à dignidade da pessoa humana, o princípio da proibição do retrocesso social toma grande importância no nosso Estado Contemporâneo, como garantia da segurança jurídica e à preservação dos direitos já adquiridos.

Como já tratado, o nosso Estado, mesmo com seu cunho Social, encontra sérias dificuldades em concretizar as prestações sociais, por diversos motivos, como falta de orçamento, falta de estrutura, flexibilização da intervenção estatal motivada pela minimalização de gastos e maximização de lucros, espelho do capitalismo.

\section{PRINCÍPIOS FUNDAMENTAIS}

É necessário conceituar princípios fundamentais para a melhor compreensão do tema. Segundo Silva ${ }^{10}$, são ordenações que fazem parte de um sistema de normas, guardam valores e bens, são o fundamento e alicerce do sistema constitucional, estruturas básicas; os direitos fundamentais positivados se distinguem entre princípios político-constitucionais e jurídico constitucionais. $\mathrm{O}$ autor ${ }^{11}$ ensina que os princípios político-constitucionais são aqueles que traduzem as opções políticas contidas na Constituição, constituídos por decisões políticas fundamentais que se concretizam em normas princípios, abrangendo o sistema constitucional positivo. Constituem os arts. $1^{\circ}$ ao $4^{\circ}$ do Título I da nossa Constituição.

Já sobre os princípios jurídico-constitucionais, leciona que decorrem de normas constitucionais, são desdobramentos dos princípios político-constitucionais, ou seja, são princípios derivados, como por exemplo o princípio da isonomia, da proteção social dos trabalhadores, do ensino e cultura.

10 SILVA, José Afonso da. Curso de Direito Constitucional Positivo. 32a. edição São Paulo: Malheiros, 2009, p. 92.

11 Idem, Ibidem, p. 93. 
O autor ${ }^{12}$ fala que é mais adequado chamá-los de normas fundamentais, dividindo-os em princípios relativos à existência, forma, estrutura e tipo de Estado (listados no art. 1 da CF/88, são: princípio da Soberania, da República Federativa do Brasil e Estado Democrático de Direito), em princípios relativos à forma de governo e organização dos poderes (arts. 1० e 2o da CF/88: República e separação dos poderes), princípios relativos à organização da sociedade (princípio da livre organização social, da conveniência justa e da solidariedade, contidos no art. 3º, I, da $\mathrm{CF} / 88$ ), princípios relativos ao regime político (cidadania, dignidade da pessoa, pluralismo, soberania popular, representação política e participação popular direta, contidos no art. $1^{\circ}$, parágrafo único, da CF/88).

O autor continuando a divisão, traz os princípios relativos à prestação positiva do Estado (princípio da independência e do desenvolvimento nacional, da justiça social e da não discriminação, contidos no art. 3º, incisos II, III e IV, da CF/88), princípios relativos à comunidade internacional (independência nacional, respeito aos direitos fundamentais da pessoa humana, autodeterminação dos povos, não-intervenção, igualdade dos Estados, solução pacífica dos conflitos e defesa da paz, do repúdio ao terrorismo e ao racismo, da cooperação entre os povos e o da integração da América Latina, listados no art. 4 da CF/88).

Ainda, o mesmo autor ${ }^{13}$ ensina que os princípios fundamentais servem como base de valor para o legislador constitucional, trazendo-os para a nossa Constituição. Os princípios fundamentais possuem função ordenadora, tendo ação imediata pois devem ser usados como critério de interpretação dando coerência ao sistema.

12 Idem, Ibidem, p. 94

13 SILVA, 2009, p. 95. 


\section{PRINCÍPIO DA SEGURANÇA JURÍDICA}

Percebe-se que o princípio da proibição do retrocesso social pode ser considerado um desdobramento da segurança jurídica, pois a não observância desse princípio acarreta inevitavelmente, a insegurança jurídica. Portanto, é mais que necessário conceituar esse princípio.

Tavares $^{14}$ leciona que a segurança jurídica é decorre diretamente do estado Democrático de Direito, pois precisa-se da certeza do ordenamento vigente e o conhecimento de antemão das consequências de fazer ou deixar de fazer alguma coisa; ou seja, deve-se ter previsão legal e estabilidade da ordem jurídica.

$\mathrm{O}$ autor ensina que as cláusulas de eternidade da Constituição dotadas de supremacia, ou seja, cláusulas pétreas, garantem a estabilidade da Constituição, em que a eternização dos direitos fundamentais positivados atende o mínimo de continuidade e identidade da nossa ordem jurídica pois acima de tudo, Tavares deixa claro que "não se pode falar em segurança jurídica sem a certeza da projeção de uma estabilidade mínima da ordem jurídica". ${ }^{15}$

Leciona que a segurança jurídica abrange várias outras garantias, como por exemplo: a garantia do direito adquirido, do ato jurídico perfeito e coisa julgada, garantia contra restrições legislativas dos direitos fundamentais (proporcionalidade), a não retroatividade de leis punitivas, devido processo legal e juiz natural, garantia contra incidência do poder reformador da Constituição em cláusulas pétreas (essenciais), não violação de direitos, direito à efetividade dos direitos previstos e declarados solenemente, direito contra medidas de cunho retrocessivo (redução ou supressão de posições jurídicas já implementadas), a proibição do retrocesso em matéria de implementação de direitos fundamentais, direito à proteção da segurança pessoal, social e coletiva, direito à estabilidade máxima da ordem jurídica e da ordem constitucional. ${ }^{16}$

14 TAVARES, André Ramos. Curso de Direito Constitucional. $7^{\mathrm{a}}$ ed. São Paulo: Saraiva, 2009. p. 728.

15 TAVARES, 2009, p. 728.

16 TAVARES, 2009, p. 729. 


\section{APLICAÇÃO E JURISPRUDÊNCIA}

Nascimento leciona que na Europa, esse princípio é amplamente aceito na doutrina e jurisprudência, tendo sua previsão inclusive em constituições como a Alemã "que estabelece a vedação de qualquer tipo de ofensa ao conteúdo essencial dos direitos fundamentais". ${ }^{17}$ Importante lembrar, que a Alemanha é até hoje um Estado Social.

Segundo Tavares ${ }^{18}$, o caso real mais conhecido de aplicação desse princípio é o que originou o Acórdão 509, de 2002, do Tribunal Constitucional português, que reconheceu a inconstitucionalidade de lei que pretendia reduzir o âmbito subjetivo dos beneficiários do chamado rendimento mínimo. $\mathrm{O}$ autor explica que a mesma tese pode ser usada no Brasil no caso do bolsa-família, não ao fundamento de manter um estado assistencialista, mas sim de exigir deste Estado que ofereça um grau sempre maior, crescente, de implementação dos direitos sociais para aqueles que ainda dependem do Estado para sua sobrevivência ou vivência digna.

Sobre sua aplicabilidade no Brasil, Tremel ${ }^{19}$ leciona que para garantir os direitos dos cidadãos, o princípio tem sido fundamento de algumas decisões do Supremo Tribunal Federal, como por exemplo, o Ag. No RE 639.337/SP20:

É o que já expôs o Ministro Celso de Melo ao afirmar que o princípio da proibição do retrocesso impede, em tema de direitos fundamentais de caráter social, que sejam desconstituídas as conquistas já alcançadas pelo cidadão ou pela formação social que ela vive. Assim sendo, a cláusula que veda o retrocesso em matéria de direito a prestações positivas do Estado (como direito à educação, o direito à saúde ou o direito à segurança pública, v.g) se traduz, no processo de efeti-

17 NASCIMENTO, 2006, p. 338.

18 TAVARES, 2009, p. 733.

19 TREMEL, 2012, p. 6.

20 TREMEL apud BRASIL, Supremo Tribunal Federal. Ag. no RE 639.337/SP. Rel. Min. Celso de Melo. DJ: 15-9-11 
vação desses direitos fundamentais individuais ou coletivos, obstáculo a que os níveis concretização de tais prerrogativas, uma vez atingidos, venham a ser ulteriormente reduzidos ou suprimidos pelo Estado.

A autora ${ }^{21}$ colhe do Supremo Tribunal de Justiça uma decisão do Ministro Luiz Fux que dispõe sobre o princípio em questão:

[...] não se pugna que a isenção do IPI na aquisição seja a única e melhor forma de garantir a liberdade de movimentação às pessoas portadoras de deficiência. No entanto, enquanto o Estado não adota políticas públicas de implementação desse direito, o benefício fiscal na aquisição do próprio veículo é o único paliativo posto à disposição da pessoa portadora de deficiência física para propiciar o seu básico direito de ir e vir. Dessa forma, a sua supressão, limitação ou inviabilização por norma posterior implica em indisfarçável retrocesso social ${ }^{22}$.

Com relação a aplicação desse princípio no Brasil, colhe-se da Jurisprudência do Tribunal Catarinense ${ }^{23}$ :

AGRAVO DE INSTRUMENTO. MANDADO DE SEGURANÇA. AUTORIDADE IMPETRADA. SECRETÁRIA MUNICIPAL DE EDUCAÇÃO E CULTURA DE CAMPOS NOVOS. FORNECIMENTO DE TRANSPORTE ESCOLAR A ALUNOS DA REDE PÚBLICA MUNICIPAL DE ENSINO. OBRIGAÇÃO DO PODER PÚBLICO. EFETIVAÇÃO DO DIREITO À EDUCAÇÃO INFANTIL. PRINCÍPIO DA PROIBIÇÃO DO RETROCESSO DE POLÍTICAS PÚBLICAS. PODER JUDICIÁRIO QUE DESFRUTA DE LEGITIMAÇÃO CONSTITUCIONAL PARA

21 TREMEL, 2012, p. 7.

22 TREMEL apud BRASIL, Superior Tribunal de Justiça. REsp. 567.873 MG, Rel. Min. Luiz Fux, DJU, 25-2-04.

23 BRASIL, Tribunal de Justiça de Santa Catarina. Acesso em 30 de out de 2012. 
INTERVIR NA ATUAC̣ÃO DE ÓRGÃO ADMINISTRATIVO QUE ESTEJA A DESCUMPRIR POLÍTICA SOCIAL PREVISTA CONSTITU. CIONALMENTE AO DEIXAR DE ATENDER A PRECEITO DE DIREITO FUNDAMENTAL INDISPONÍVEL. CONSTITUIÇÃO FEDERAL. ARTS. 6, 205, 208, INC. VIII, E 211, § 4․ ESTATUTO DA CRIANÇA E DO ADOLESCENTE, ARTS. 4 E 54, INC. VII. LEI DE DIRETRIZES E BASES DA EDUCAÇÃO, ARTS. 4º, INC. VIII, E 11, INC. VI. INEXISTÊNCIA DE CIRCUNSTÂNCIA EXCEPCIONAL A JUSTIFICAR O CANCELAMENTO DO SERVIÇO. RECURSO PROVIDO (TJSC, AI. 2011.088547-1, rel. Min. Nelson Schaefer Martins, j. 11-09-12).

Interessante mostrar que aqui o Poder Público deixou de aplicar políticas públicas previstas constitucionalmente para efetivar um direito básico, no caso, à educação. Esse princípio foi aplicado no julgamento deste Agravo de Instrumento no sentido de vedar o retrocesso da política pública em si, implantada para fortalecer o direito em questão pois, sem ela, a efetivação do direito social seria posta em risco. Passa-se à análise do seguinte julgado:

SENTENÇA. JULGAMENTO EXTRA PETITA. PEDIDO CIRCUNSCRITO AO ADICIONAL DE PERICULOSIDADE . CONCESSÃO, ENTRETANTO, DE OBJETO DIVERSO, OU SEJA, ADICIONAL DE INSALUBRIDADE. NULIDADE RECONHECIDA. ALTERAÇÃO DO ART. 37, § $3^{\circ}$, DA CF DECORRENTE DA EC N. 19/98. DIREITO SOCIAL DO SERVIDOR PÚBLICO NÃO AFETADO. RECURSO PROVIDO. NO ESTADO DEMOCRÁTICO DE DIREITO VIGE O PRINCÍPIO DO RETROCESSO SOCIAL (TJSC, Ap. 2003.005570-3, rel. Des. Cesar Abreu, j. 13-04-04). 
Os autores dessa ação processaram o Município de Joaçaba/ SC, objetivando o recebimento de adicional de insalubridade. O pedido foi julgado procedente e, irresignado, o Município recorreu. Por seu turno, o Relator negou provimento ao recurso e fundamentou sua decisão usando como base o princípio da proibição do retrocesso social. Colhe-se do seu voto:

No particular da alteração advinda da EC n. 19/98, dois fundamentos devem ser explorados: $\mathrm{O}$ primeiro, circunscrito ao fato de que haveria direito em relação ao período pretérito à Emenda. O segundo, no sentido de que, em verdade, constituem os direitos sociais cláusulas pétreas que não podem ser suprimidas por Emenda decorrente de processo legislativo derivado. É que os direitos sociais, enquanto direitos fundamentais de 2a Geração, são pétreas, à medida que refletem direitos e garantias individuais do trabalhador (CF, art. $60, \S 4^{\circ}$, IV). E os direitos sociais, uma vez conquistados e obtidos, proporcionam um certo grau de realização, passando a constituir, simultaneamente, uma garantia institucional e um direito subjetivo. Aliás, no Estado Democrático de Direito vige o princípio da proibição do retrocesso social (TJSC, Ap. 2003.005570-3, rel. Des. Cesar Abreu, j. 13-04-04, p. 2).

Dessarte, o insigne Relator discorreu sobre a importância dos direitos sociais, uma vez que são cláusulas pétreas e, portanto, imutáveis, complementando que em razão de sermos um Estado Democrático de Direito, vige o princípio da proibição do retrocesso social.

Agora, analisar-se-á o último julgado da Corte catarinense:

EMBARGOS À EXECUÇÃO. CÉDULA RURAL PIGNORATÍCIA. CAPITALIZAÇÃO MENSAL DE JUROS. INVIABILIDADE. PRINCÍPIO DA ESPECIALIDADE. PREVALÊNCIA DO DECRETO-LEI N. 167/1967, QUE PREVÊ PERIODICIDADE NÃO INFERIOR À SEMES. 
TRALIDADE. MEDIDA PROVISÓRIA N. 2.170/2000, QUE DEVE SER INTERPRETADA RESTRITIVAMENTE, SOB PENA DE ADMITIR-SE A PRÁTICA DO RETROCESSO SOCIAL E MALFERIMENTO AO PRINCÍPIO DA IGUALDADE. TRATAMENTO PRIVILEGIADO DO CRÉDITO RURAL, VOLTADO A PRODUÇÃO DE BENS DE SUBSISTÊNCIA, DE BAIXA LUCRATIVIDADE E ALTO RISCO, PELOS IMPREVISTOS DA NATUREZA. RECURSO DESPROVIDO. A Medida Provisória n. 2.170-36, de 23-8-2001, que admite a capitalização mensal dos juros, não se aplica às cédulas de crédito rural, comercial e industrial, as quais contam com legislação própria, que regula a matéria (TJSC, Ap. 2008.045047-4, rel. Des. Cesar Abreu, j. 05-05-09).

A lide versa sobre a Lei que define que o Conselho Monetário Nacional deve limitar as taxas de juros e encargos para o crédito rural. E sobre o porquê da vedação da capitação de juros, teceu o seguinte comentário:

Aliás, outro o entendimento, seria admitir-se que o legislador estaria a praticar o que se denomina de "retrocesso social", malferindo o princípio da igualdade, ao colocar num mesmo patamar aquele que financia com o suor do seu trabalho a produção de alimentos e o que usa do empréstimo para deleite pessoal, por exemplo, para aquisição de automóvel de passeio (TJSC, Ap. 2008.045047-4, rel. Des. Cesar Abreu, j. 05-05-09, p. 3).

Para Barcellos e Barroso ${ }^{24}$, o princípio da proibição do retrocesso social é a impossibilidade de invalidação da revogação de normas que, regulamentando o princípio, concedam ou ampliem direitos fundamentais, sem que a revogação em questão seja acompanhada de uma política substitutiva equivalente.

24 BARCELLOS, Ana Paula de; BARROSO, Luís Roberto. O Começo da História. A Nova Interpretação Constitucional e o Papel dos Princípios no Direito Brasileiro. p. 69. 
Nessa seara, percebe-se que o princípio da proibição do retrocesso social é uma ferramenta para se proteger os direitos fundamentais sociais, impedindo o Estado de modificar os direitos sociais ou flexibiliza-los; então, frente à modificação da sociedade de um direito fundamental é moldado, caracteriza-se o retrocesso social, trazendo à sociedade insegurança jurídica.

\subsection{Análise do julgado Ag. No RE 639.337/SP do STF}

O julgado Ag. No RE 639.337/SP25 é um marco muito importante para a aplicação desse princípio no Brasil, importante fazer uma breve análise da ementa em sua íntegra:

CRIANÇA DE ATÉ CINCO ANOS DE IDADE - ATENDIMENTO EM CRECHE E EM PRÉ-ESCOLA - [...] OBRIGAÇÃO ESTATAL DE RESPEITAR OS DIREITOS DAS CRIANÇAS - EDUCAÇÃO INFANTIL - DIREITO ASSEGURADO PELO PRÓPRIO TEXTO CONSTITUCIONAL (CF, ART. 208, IV, NA REDAÇÃO DADA PELA EC No 53/2006) [...] DIGNIDADE DA PESSOA HUMANA E VEDAC̣̃̃O DO RETROCESSO SOCIAL [...] A cláusula da reserva do possível - que não pode ser invocada, pelo Poder Público, com o propósito de fraudar, de frustrar e de inviabilizar a implementação de políticas públicas definidas na própria Constituição - encontra insuperável limitação na garantia constitucional do mínimo existencial, que representa, no contexto de nosso ordenamento positivo, emanação direta do postulado da essencial dignidade da pessoa humana. Doutrina. Precedentes. [...] A PROIBIÇÃO DO RETROCESSO SOCIAL COMO OBSTÁCULO CONSTITU. CIONAL À FRUSTRAÇÃO E AO INADIMPLEMENTO, PELO PODER PÚBlICO, DE DIREITOS PRESTACIONAIS. - O princípio da proibição do retrocesso impede, em tema de

25 BRASIL, Supremo Tribunal Federal. <http://redir.stf.jus.br/paginadorpub/paginador.jsp?docTP=AC\&docID=627428> Acesso em 29 de out de 2012. 
direitos fundamentais de caráter social, que sejam desconstituídas as conquistas já alcançadas pelo cidadão ou pela formação socialem que ele vive. - A cláusula que veda o retrocesso em matéria de direitos a prestações positivas do Estado (como o direito à educação, o direito à saúde ou o direito à segurança pública, v.g.) traduz, no processo de efetivação desses direitos fundamentais individuais ou coletivos, obstáculo a que os níveis de concretização de tais prerrogativas, uma vez atingidos, venham a ser ulteriormente reduzidos ou suprimidos pelo Estado. Doutrina. Em conseqüência desse princípio, o Estado, após haver reconhecido os direitos prestacionais, assume o dever não só de torná-los efetivos, mas, também, se obriga, sob pena de transgressão ao texto constitucional, a preservá-los, abstendo-se de frustrar - mediante supressão total ou parcial - os direitos sociais já concretizados. [...] (STF, Ag. No RE 639.337/SP, Min. Rel. Celso de Mello, j. 23-0811, grifei).

A ementa do julgado carrega consigo o conceito do princípio da proibição do retrocesso social e sua importância, trazendo eficácia ao direito constitucional à educação e obrigando o Estado a cumprir políticas para sua efetivação; aqui inclusive, sob pena de multa diária.

O Ministro Celso de Mello em seu voto ${ }^{26}$, sobre a concretização dos direitos essenciais, ensina que sua eficácia não pode jamais ser comprometida, sendo o direito à educação um direito público subjetivo do particular, que pode exigir o cumprimento por parte do Estado.

Estado por sua vez, não pode utilizar-se do princípio da reserva do possível para abster-se de tais obrigações, omitindo-se do encargo de efetivar tais direitos, pondo em risco não só a eficácia do direito em questão, mas da própria constituição. $\mathrm{O}$ princípio da reserva do possível consiste em o Estado atender

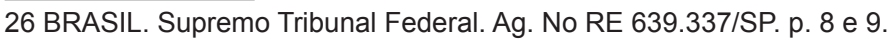


as demandas sociais dentro de um limite de razoabilidade e respeitando o seu orçamento, o que não pode ser aplicado aqui, já que estamos falando em mínimo existencial e em direitos sociais consagrados como cláusulas pétreas ${ }^{27}$.

E mais, o Ministro também nos mostra que a inércia do Estado nas prestações dos direitos sociais básicos deve ser repelida, pois é uma das causas geradoras dos processos informais de mudança da constituição. ${ }^{28}$

O Ministro explica que não deve o Estado aplicar as normas constitucionais apenas quando lhe for conveniente, pois essa atitude pode acarretar na desvalorização e no desprestígio da constituição podendo gerar um processo de mudança da constituição. ${ }^{29}$

Como corolário, o não cumprimento desse princípio, implica na instabilidade da ordem jurídica, trazendo principalmente a insustentabilidade de um Estado Social, como fica evidente no julgado analisado, pondo em risco a nossa Constituição.

\section{CONCLUSÃO}

O presente trabalho teve como objetivo principal mostrar a importância desse novo princípio que, como visto, serve para assegurar direitos já adquiridos em matéria de cunho social, abrangendo toda e qualquer forma de redução das conquistas sociais, preservando não só a dignidade da pessoa humana como também, a segurança jurídica.

Dentre seus fundamentos, percebe-se que a conquista dos direitos sociais está estritamente ligada às lutas por um mínimo existencial, condições dignas de trabalho e subsistência; também por isso, a importância de se assegurar esses direitos e vedar qualquer tipo de flexibilização das conquistas adquiridas.

27 BRASIL. Supremo Tribunal Federal. Ag. No RE 639.337/SP. p. 9. 28 BRASIL. Supremo Tribunal Federal. Ag. No RE 639.337/SP. p. 14. 29 BRASIL. Supremo Tribunal Federal. Ag. No RE 639.337/SP. p. 16. 
Segundo o que foi explanado, o Estado como agente promovedor de justiça e igualdade social foi diferente ao longo de sua história, primeiro priorizando as liberdades públicas para somente após muitas lutas sociais, passar a promover os direitos sociais.

Observa-se que primeiro o Estado se abstêm das relações humanas em sociedade para em um segundo momento, interferir nessas relações prestando serviços básicos como saúde, educação, alimentação, moradia etc.

Na contemporaneidade, fenômenos como a diminuição da máquina estatal com a consequente diminuição de incentivos nos setores sociais, constantes privatizações, o aumento do desemprego, a diminuição de benefícios sociais e o aumento dos níveis de pobreza, fazem parte do nosso cotidiano moderno e atinge grande parte dos países capitalistas.

A falta de efetividade das normas constitucionais contribui decisivamente para o comprometimento da credibilidade da Constituição e a segurança jurídica; os textos constitucionais contemplam muitas promessas, mas com pouca eficácia social, criando-se um profundo abismo entre o mundo do "dever ser" e a realidade, que corrói a crença na constituição como norma.

Então, é muito comum ver a constituição como um depósito de utopias e de proclamações de pouca aplicação prática, e que, implica em sua descredibilidade, de modo que reduzir a exclusão social e garantir concretamente o gozo dos direitos fundamentais são grandes desafios atualmente.

Para isso, precisa-se formular e implementar as políticas públicas necessárias à proteção dos direitos humanos, e no tocante aos direitos já adquiridos e positivados, mantê-los sem flexibilizações ou vedações.

Como os direitos sociais estão diretamente ligados à dignidade da pessoa humana, o princípio da proibição do retrocesso social toma grande importância no nosso Estado Contemporâneo, como garantia da segurança jurídica e à preservação dos direitos já adquiridos. 
Por fim, percebe-se a importância dos objetivos traçados por nossa constituição, como metas a ser seguidas, visando o alcance da cidadania plena, ou seja, a concretização da igualdade social da forma em que todos possam ter não só um mínimo existencial, pois o valor "vida" na Constituição brasileira, não contém apenas o significado direito à vida, mas sim o direito à vida digna.

Conclui-se que a não observância do princípio em questão retrocedendo em matérias de cunho social significa desrespeitar a segurança jurídica e colocar em risco a própria Constituição, instalando a instabilidade da ordem jurídica e a insustentabilidade de um Estado Social.

\section{REFERÊNCIAS}

BARCELLOS, Ana Paula de; BARROSO, Luís Roberto. O Começo da História: A Nova Interpretação Constitucional e o Papel dos Princípios no Direito Brasileiro. Disponível na internet: <http://www.egov.ufsc.br/portal/ sites/default/files/anexos/31274-34849-1-PB.pdf >. Acesso em: 8 set 2012.

BRASIL. Superior Tribunal Federal. Acesso em 24 de maio de 2015.

BRASIL. Tribunal de Justiça de Santa Catarina. Acesso em 24 de maio de 2015.

NASCIMENTO, Rafael. O princípio da proporcionalidade como via de aferição do retrocesso social. Revista Petardo, Anuário PET. Santa Catarina: Fundação Boiteux. 2006.

SARLET, Ingo Wolfgang. Proibição de Retrocesso, Dignidade da Pessoa Humana e Direitos Sociais: manifestação de um constitucionalismo dirigente possível. Revista do Instituto de Hermenêutica Jurídica. Disponível na internet: http://tex.pro.br/tex/images/stories/PDF_artigos/proibicao_ingo_ wlfgang_sarlett.pdf $>$. Acesso em: 9 set 2012.

SILVA, José Afonso da. Curso de Direito Constitucional Positivo. 32a. edição São Paulo: Malheiros, 2009.

TAVARES, André Ramos. Curso de Direito Constitucional. 7a ed. São Paulo: Saraiva, 2009. 
TREMEL, Rosangela. Princípio da Proibição do Retrocesso: Sua Importância e Necessidade de Ampliação do Entrenchment para Proteção dos Hipossuficientes. Disponível em: <http://www.advocaciapasold.com.br/artigos/arquivos/ artigo_principio_do_nao_retrocesso_profa_rosangela_tremel.pdf $>$ Acesso em: 10 out 2012 .

Artigo recebido em 03/08/2015

Artigo aprovado em 28/08/2015 